\title{
Long-term impacts of battery electric vehicles on the German electricity system
}

\author{
H.U. Heinrichs ${ }^{1, a}$ and P. Jochem ${ }^{2}$ \\ 1 Forschungszentrum Jülich, Institute for Energy and Climate Research - System Analysis \\ and Technology Evaluation (IEK-STE), Wilhelm-Johnen Strasse, 52425 Jülich, Germany \\ 2 Karlsruhe Institute for Technology (KIT), Institute for Industrial Production (IIP), \\ Hertzstrasse 16a, 76187 Karlsruhe, Germany
}

\begin{abstract}
The emerging market for electric vehicles gives rise to an additional electricity demand. This new electricity demand will affect the electricity system. For quantifying those impacts a model-based approach, which covers long-term time horizons is necessary in order to consider the long lasting investment paths in electricity systems and the market development of electric mobility. Therefore, we apply a bottom-up electricity system model showing a detailed spatial resolution for different development paths of electric mobility in Germany until 2030. This model is based on a linear optimization which minimizes the discounted costs of the electricity system. We observe an increase of electricity exchange between countries and electricity generated by renewable energy sources. One major result turns out to be that electric vehicles can be integrated in the electricity system without increasing the system costs when a controlled (postponing) charging strategy for electric vehicles is applied. The impact on the power plant portfolio is insignificant. Another important side effect of electric vehicles is their substantial contribution to decreasing $\mathrm{CO}_{2}$ emissions of the German transport sector. Hence, electric mobility might be an integral part of a sustainable energy system of tomorrow.
\end{abstract}

\section{Introduction}

Since the new millennium, battery electric vehicles $(B E V)^{1}$ undergo a renaissance due to recent achievements in battery technology. The chances of BEV to reach commercial competitiveness are widely discussed [1]. In this context the battery costs and the corresponding limited range - are identified as the main barrier for BEV to enter mass market. These costs have been falling significantly during the last years and the forecasts are promising [2]. Further barriers are the limited supply of BEV

a e-mail: h.heinrichs@fz-juelich.de

1 We define BEV as all electric vehicles, which recharge their battery from the electricity grid, i.e. including Plug-In Hybrid Electric Vehicles (PHEV) - sometimes referred as Plug-In Electric Vehicles (PEV). 
types by vehicle manufacturers, the limited public infrastructure (even though most users charge their vehicles at private charging stations, (cf. [3]) as well as several psychological concerns from potential users (cf. [4]). Some psychological concerns refer to the ambiguous environmental impacts of $\mathrm{BEV}[5,6]$. Aspects like the production and recycling of batteries, the generation of electricity and the development of internal combustion engines determine the environmental impacts of BEV compared to alternative transportation modes. Furthermore, this environmental impact is dependent on the "additional" electricity generation during vehicle usage. This is already analyzed by studies focusing on the relevant technology and economics [7-9]. From the energy-economic point of view it is fairly obvious, that it will be necessary to implement controlled vehicle charging. Its significance depends on the additional electricity demand (i.e. quantity of electric vehicles and their charging rate) as well as the grid condition (i.e. the share of volatile electricity supply and the grid quality) $[3,10]$. Whereas the additional energy demand is marginal, the additional load might be significant when charging processes take place simultaneously [9].

The renaissance of BEV is accompanied by several fundamental changes in the European and German energy system. Historically a centralized, demand driven system, it is currently evolving into a more decentralized supply driven one. The main drivers who facilitate this development are the liberalization of the European energy markets, the introduction of the European emission trading system (EU-ETS) and the increasing stochastic feed-in by renewable energy sources (RES). This leads to several challenges for the energy system which might be amongst others extenuated by reinforcing and extending electricity grids and storages as well as increasing the elasticity of electricity demand [11]. From this energy economic perspective, the increasing (but flexible) electricity demand from BEV might support or impede the German efforts in greenhouse gas mitigation.

A controlled charging of BEV might have a positive influence by providing a substantial load shifting potential [12]. Such a load shift potential can for example help to integrate further renewable energy sources into the electricity grid. However, a more decentralized energy system and local specific market penetration of BEV $[13,14]$ makes a regional analysis of the corresponding challenges inevitable. In the following, we therefore consider model grid constraints on the transport grid level as well as regional specific electricity demand and BEV market penetration, building up on results presented in [15]. As the model complexity is already high and the data availability is poor, we regard the 402 German NUTS- $3^{2}$ regions as a good compromise - even though we are aware that the local impact on the distribution grid from BEV might be highly relevant [17-19].

The first political target for BEV in Germany was announced as part of the Energy Concept of the German government in 2010 [20]. Therein the government states the target to reach 1 million BEV in 2020 and 6 million in 2030. To reach these targets the government funds research in all related fields and qualifies electric vehicles for a motor vehicle tax reduction. In contrast to other countries, which also decided ambitious market targets and mostly implemented purchase subsidies (e.g. [21]), there are no other direct subsidies for BEV in Germany, yet. On the European level electric vehicles benefit from the Regulations 443/2009 and 333/2014 [22] which considerably restrict the average specific emission values for passenger cars (M1 class) sold in Europe for all vehicle manufacturers. For 2020 the average emissions for all new registered cars per manufacturer are restricted to $95 \mathrm{~g}$ of $\mathrm{CO}_{2} / \mathrm{km}$ and for $2030 \mathrm{a}$ target of about $70 \mathrm{~g}$ of $\mathrm{CO}_{2} / \mathrm{km}$ is under discussion [23]. This value is very ambitious

${ }^{2}$ NUTS (Nomenclature of territorial units for statistics) describes the European regions in different hierarchical levels and ranges from NUTS 0 (countries) to NUTS 3 (counties or districts) [16]. 
for conventional vehicles. However, as $\mathrm{CO}_{2}$ emissions from the charging process of $\mathrm{BEV}$ are neglected and they are considered as zero emission vehicles, the regulation is seen as a relevant driver for car manufacturers to enter the BEV market [23]. Despite those political targets the car stock of BEV in Germany is still at a very low level (i.e. below $1 \%$ or about 19,000 vehicles), however, at accelerated growth $(+40.8 \%$ in 2014 , i.e. $8,522[24])$.

\section{Analysis approach}

Since we focus on the possible long-term impacts of BEV on the German electricity system. The chosen approach must be able to deal with the following two aspects: the long-term development of the German electricity system and of the BEV stock in Germany. The first aspect calls for a model which can calculate power plant expansions as well as utilization. Optimizing bottom-up energy or electricity models are well known to be capable of such an application [26]. Therefore we chose the PERSEUS-NET-EMO model $[15,27]$ which represents the German electricity system on a high level of technical detail. This model divides Germany into its more than 400 NUTS-3 regions each associated with its own electricity demand and supply as well as its heat demand. The heat demand is needed to account for CHP power plants in an adequate way. Figure 1 shows the schematic model structure of each region. Those regions are combined with a GIS $^{3}$ referenced DC load flow model for the German transmission grid. We apply a nodal pricing approach here, where all flows in the grid are calculated, assigned with regional specific generation costs and all power flow limits for each grid element are respected. This allows a identification of grid constraints. The grid data are taken from the grid map of ENTSO-E [28] while the assumed grid expansions in Germany are mainly based on the EnLAG law [29]. The latter represents a more realistic assumption compared to the current scenarios of the German Grid Agency [30]. However, the grid expansion plans of the German Grid Agency show substantial delays [31] and therefore bear a high level of uncertainty. Additionally PERSEUS-NET-EMO allows to calculate $\mathrm{CO}_{2}$ emissions of power plants which provides a basis to compare BEV and conventional cars in terms of those emissions. From a methodological point of view PERSEUS-NET-EMO can be characterized as a linear optimization over a time horizon until 2030 which takes economic parameters (i.e. investments, fixed and variable costs) as well as technical parameters (i.e. efficiency, life time, operation constraints, grid development) of all technologies in the German electricity system into account. Its objective function minimizes the overall system costs. The covered time horizon until 2030 is divided into 5 year periods and each year is divided into 126 time slices representing typical days during a year. The results of this model do not claim to predict the future. However, they can serve to inform public and political debates in a "what-if" framework [32].

The second aspect, to address possible BEV stock developments in Germany, requires an approach which allows to derive consistent characteristics for BEV in terms of load and demand. It has to be suitable to be combined with the aforementioned approach to aspect one (long term development of the German electricity system) in order to allow for an integrated analysis. Therefore and due to the different driver's needs in the various regions the applied BEV approach shows the same spatial resolution. In the following we are considering only mobility patterns of private cars and assume implicitly that business cars are used similarly [33,34]. In limiting our focus

\footnotetext{
${ }^{3}$ A GIS (geographic information system) is a system to handle and present spatial data conveniently. In this analysis the commercial software ArcGis $^{\mathrm{TM}}$ from ESRI $^{\circledR}$ is applied.
} 


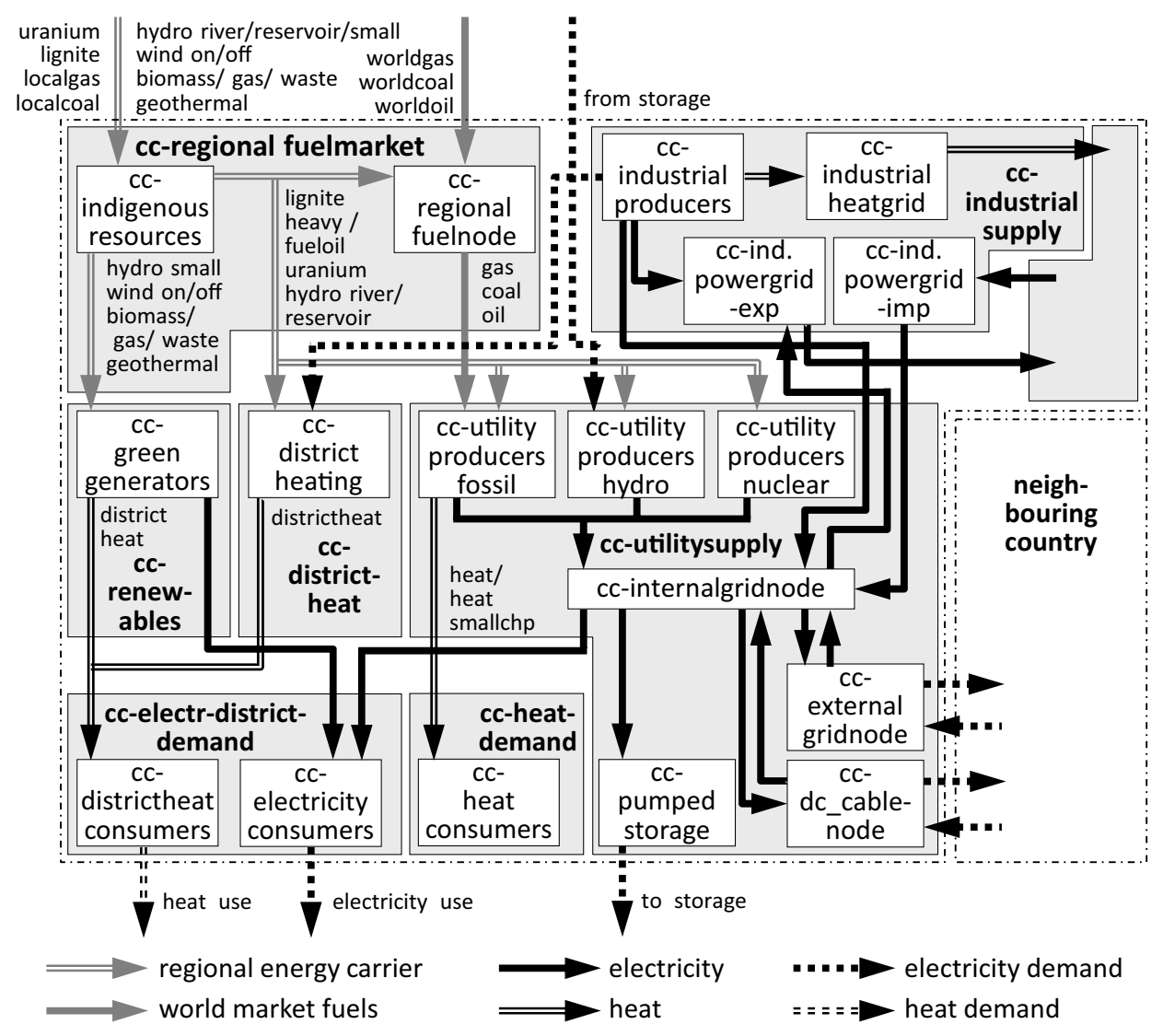

Fig. 1. Overview of the underlying model structure in PERSEUS (cc: region code) [25].

on cars we can take the MID mobility survey as a profound data basis [35] which allows an in-depth analysis of driving patterns and mileage. Those characteristics can be used to derive the electrical load and electricity demand of BEV. To do so we compare the total cost of ownership of a pure BEV and a plug-in hybrid electric vehicle (PHEV) with a car powered by an internal combustion engine as described in $[13,14]$. From this comparison we derive a minimal yearly mileage a BEV or PHEV needs to become competitive with a conventional car. Beside this minimal yearly mileage only those car owners are counted to be eligible for a BEV who show a driving behavior compatible with the technical limitations of a BEV with respect to available charging infrastructure and daily mileage. Those framework conditions change until 2030 (i.e. more infrastructure allow for longer daily mileages or an own parking space is not required anymore in later years cf. [15] Chapter 5.3.3). The average driving pattern of those eligible car owners form the basis to derive the load shift potential of BEV. Two extreme charging scenarios are applied to the eligible driving patterns resulting in two load curves which state the limits of the load shift potential. The first extreme charging strategy describes a complete charging each time a charging station is available. The second extreme charging strategy assumes the latest possible charging only for the next trip or trips which is needed to reach the next charging option. Even though both charging strategies need the same amount of electricity, from an electricity systems point of view the exact point in time of the load is highly relevant as electricity can not be stored economically to a sufficient big extent. Beside 
Table 1. Scenario parameters.

\begin{tabular}{lccc}
\hline & Pessimistic & Reference & Optimistic \\
\hline Load control & - & load shifting & load shifting \\
Load infrastructure & at home & at home + work & (mostly) everywhere \\
Load load capacity & $16 \mathrm{~A}$, single phase & $16 \mathrm{~A}$, tri phase & $250-400 \mathrm{~A}$, tri phase \\
Battery price & $-3.3 \% / \mathrm{a}$ & $-3.7 \% / \mathrm{a}$ & $-4 \% / \mathrm{a}$ \\
Specific EV demand & $-0.5 \% / \mathrm{a}$ & $-0.9 \% / \mathrm{a}$ & $-1.3 \% / \mathrm{a}$ \\
Fuel prices & $+3.9 \%$ crudeoil $/ \mathrm{a}$ & $+3.9 \%_{\text {crudeoil }} / \mathrm{a}$ & $+3 \%_{\text {crudeoil }} / \mathrm{a}$ \\
EU RES target 2030 & $42 \%_{\text {electricity }}$ & $42 \%$ electricity & $48 \%_{\text {electricity }}$ \\
EU CO $\mathrm{CO}_{2}$ target 2030 & $\sim-50 \% 2005$ & $\sim-50 \% 2005$ & $\sim-53 \%$ 2005 \\
\hline
\end{tabular}

this the weighted yearly mileage and share of BEV or PHEV in car purchases are used to calculate the yearly electricity demand.

The derived limits of the load shift potential of pure and plug-in hybrid BEV are implemented in the electricity system model. In between both load curves the electricity system model is free to choose those load curves which allow for a cost minimization without restricting the mobility needs. Beside this coupling of both approaches the marginal generation costs of electricity derived from PERSEUS-NETEMO feed in the calculation of the total cost of ownership of the BEV. Insofar both approaches have to be iterated until their results converge. In this paper we apply those coupled approaches to three scenarios which ranges from a pessimistic (PES), a moderate (REF) and an optimistic (OPT) developments for electric vehicles (s. Table 1). The first three scenario parameters are related to the load infrastructure. While the 'Reference' and 'Optimistic' scenario allow for an optimized load strategy from an electricity systems perspective between the aforementioned two boundaries of the BEV load shift potential, in the 'Pessimistic' scenario the load strategy is exogenously fixed to the first extreme charging strategy (a complete charging each time a charging station is available) described above. The latter is assumed on the basis that the BEV penetration in the 'Pessimistic' scenario is too low from an economic point of view for a load infrastructure which is enabled for load shifting. The second and third scenario parameters assume increasing degrees of freedom for charging a BEV ('Pessimistic' < 'Reference' < 'Optimistic'). The next three scenario parameters describe mainly economical framework conditions which promote higher BEV market penetrations in the 'Optimistic' scenario. The last two parameters apply to the European level and assume environmental framework conditions. While the 'Pessimistic' and 'Reference' scenario show the same values, the 'Optimistic' exhibit more ambitious environmental targets.

This allows us to highlight possible differences in the electricity system induced by varying EV shares. However, these scenarios do not state a classical sensitivity analysis, but a scenario analysis focusing on different possible stories about the future with a consistent set of parameters [37]. Beside those scenario parameters shown in Table 1 several assumptions have to be made which do not differ between the scenarios (i.e electricity demand increase of $1 \%$ /a, nuclear phase-out until 2022, current status-quo and foreseeable expansions of transmission grid capacities). In contrast to other studies we excluded a re-injection of electricity from the battery into the grid due to the high battery degradation costs [36]. Additionally, we assume a $\mathrm{CO}_{2}$ emissions cap for the EU ETS for all scenarios which also has to cover the additional electricity demand by BEV. All framework conditions on an European level which are not assumed exogenously (i.e. the electricity exchange) are derived from another PERSEUS model covering an European scale [15,25]. 


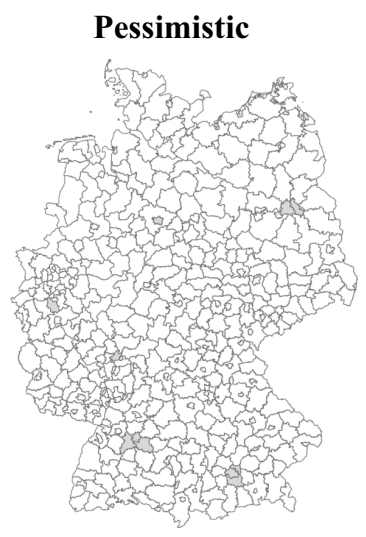

$\sim 0.2$ mio. BEV

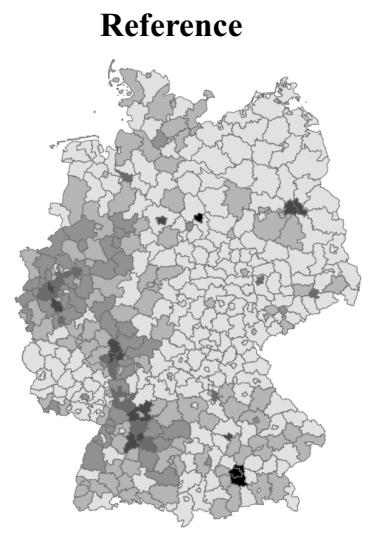

$\sim 9.6$ mio. BEV

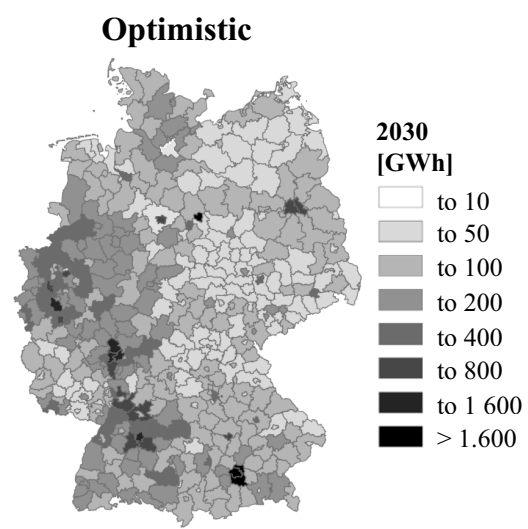

$\sim 22$ mio. BEV

Fig. 2. Spatial distributed electricity demand of BEV in 2030 [15].

\section{Results}

The results described in this section focus mainly on those showing the impacts of $\mathrm{BEV}$ on the German electricity system. These include (a) the electricity demand of $\mathrm{BEV}$, (b) the load curves of BEV, (c) the electricity production, (d) the average marginal costs of electricity generation as well as (e) the $\mathrm{CO}_{2}$ emissions. The spatial distributed electricity demand of BEV in Germany as shown in Figure 2 illustrates the influence of the assumed framework conditions in the chosen scenarios. In the 'Pessimistic' scenario hardly any electricity demand of BEV occurs in our results until 2030. This electricity demand is most notably concentrated to urban areas like Munich, Berlin or Stuttgart and sums up to nearly $0.5 \mathrm{TWh} / \mathrm{a}$ in 2030 which equals roughly $0.09 \%$ of Germany's overall electricity demand in that year. This trend of concentrating electricity demand for $\mathrm{BEV}$ in urban regions hold true for both other scenarios as well. In the 'Reference' and the 'Optimistic' scenario the electricity demands of BEV sums up to $43 \mathrm{TWh}(\sim 7 \%)$ and $60 \mathrm{TWh}(\sim 9 \%)$ respectively. This shows that even under the most supportive circumstances the electricity demand of BEV only reaches up to $\sim 9 \%$ of Germany's overall electricity demand in 2030 . As we exclude re-injection of electricity from the battery into the grid due to the high battery degradation costs this $9 \%$ contains only the electricity demand for driving needs. Compared to this BEV share the political targets to reduce the gross electricity demand in Germany by 10\% until 2020 and by $25 \%$ until 2050 are roughly equal or even higher [20]. Additionally the political targets for electric vehicles are only met completely in the 'Optimistic' scenario with BEV penetrations of $\sim 1,5$ million BEV in 2020 and $\sim 22$ million BEV in 2030, while in the 'Pessimistic' scenario none of the targets are met $(\sim 120,000 \mathrm{BEV}$ in $2020, \sim 200,000 \mathrm{BEV}$ in 2030$)$. In the 'Reference' scenario only the later target for 2030 is met $(\sim 400,000 \mathrm{BEV}$ in $2020, \sim 9.6$ million $\mathrm{BEV}$ in 2030).

Figure 3 shows on the left side the normalized daily load curves for a typical winter weekday. They are calculated by our model approach for those scenarios with a load control option. Only the load curve for the 'Pessimistic' scenario is a model input and describes the load for an 'immediate full'-charging strategy, one extreme of the load shift potential of BEV here. Compared to the other load curves it is quite obvious that they differ substantially from this charging strategy. They exhibit more of the characteristics of a 'as late and as least as possible'-charging strategy which represents the other extreme of the load shift potential of BEV in our approach. The differences 
(a)

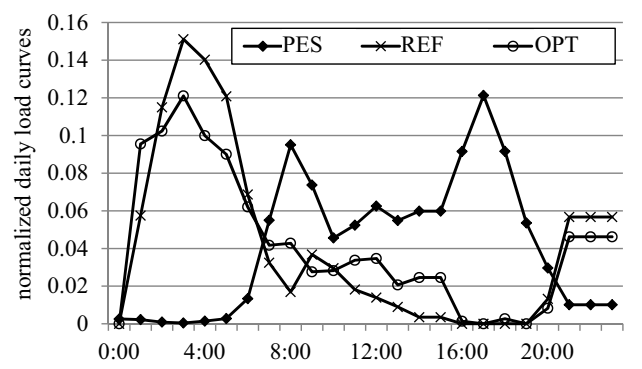

(b)

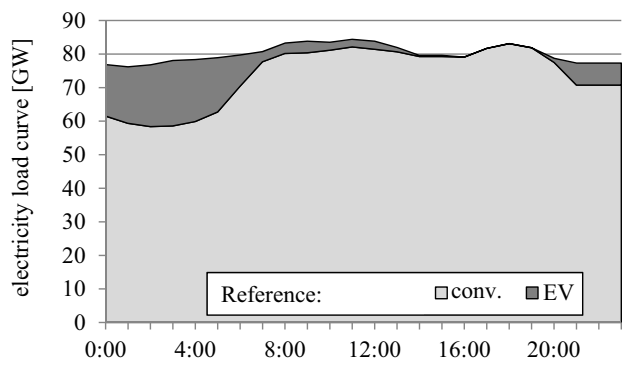

Fig. 3. Normalized (a) and absolute (b) daily load curves of BEV and conventional demand (b) for a winter weekday in 2030 [15].

in the load curves between the 'Reference' and the 'Optimistic' scenario occurs due to the assumed charging infrastructure which is more developed in the 'Optimistic' scenario. This means the 'Optimistic' scenario offers more options during the day to charge the BEV which leads to a lower normalized peak in the morning. However, due to the overall higher BEV penetration in this scenario the absolute peak is higher compared to the 'Reference' scenario. To bring out the most prominent reason for the resulting load curves the cumulative electricity load of Germany for the 'Reference' scenario in 2030 is depicted on the right side in Figure 3. This chart shows that the electricity demand of $\mathrm{BEV}$ is used to fill the valleys of the conventional electricity demand as well as to utilize more electricity from photovoltaics before and during midday.

To show the effect of BEV on the electricity generation the 'Pessimistic' and the 'Reference' scenario are compared to each other in Figure 4 for the year 2030 and the electricity generation of 2007 is added as well for reference purposes. In the 'Optimistic' scenario the higher RES target dominates the effects of BEV. Therefore we focus on the other scenarios in the following. Both scenarios in Figure 4 show an increase in wind offshore in northern Germany as well as a smaller more decentralized expansion of photovoltaics mainly in southern Germany. Additionally lignite fired electricity generation decreases while the share of hard-coal remains roughly constant and gas power plants increase until 2030. This is closely related to the flexibility of those power plants operation which increases in importance in an electricity system with a high share of RES. Despite these overall developments of the German electricity generation which occurs in all scenarios some differences due to electric vehicles and their load shift potential exist. The most prominent difference is the regional distribution of the electricity generation. In scenarios with a load control option less electricity is produced in Bavaria due to the more efficient utilization of the electricity grid. Additionally the regional differences sum up to more RES $(\sim 23$ TWh $)$, hard-coal $(\sim 35 \mathrm{TWh})$ and lignite $(\sim 1.3 \mathrm{TWh})$ as well as less gas $(\sim 16 \mathrm{TWh})$ in the 'Reference' scenario compared to the 'Pessimistic' scenario in 2030. The 'Optimistic' scenario shows more RES ( 97 TWh) and hard-coal ( $\sim 15 \mathrm{TWh})$ as well as less gas $(\sim 25 \mathrm{TWh})$ and lignite $(\sim 17 \mathrm{TWh})$ compared to the 'Pessimistic' scenario in 2030. These effects are closely related to the valley filling load curves of BEV which promote the operation of base and medium load power plants like lignite and hardcoal fired power plants. The higher amount of RES in the 'Reference' scenario results from the assumed RES share target (s. Table 1) which leads to an absolute higher RES amount in scenarios with higher electricity demands. The differences in the fossil electricity mix of all scenarios are relatively small compared to the overall electricity 

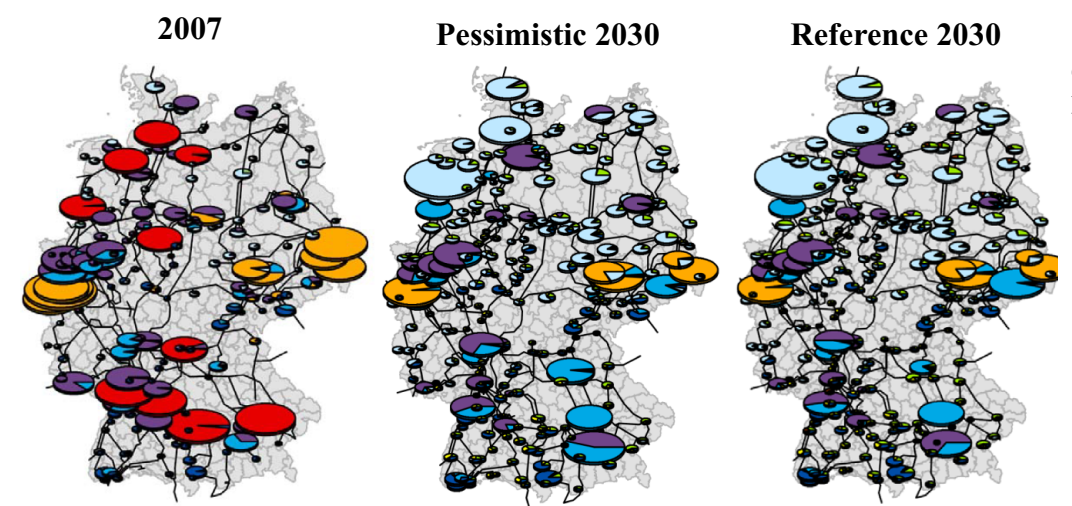

electricity

production [TWh]

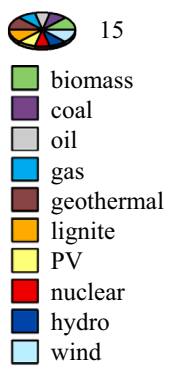

Fig. 4. Comparison of the spatial distributed electricity production for the 'Pessimistic' and 'Reference' scenario in Germany in 2007 and 2030 [15].
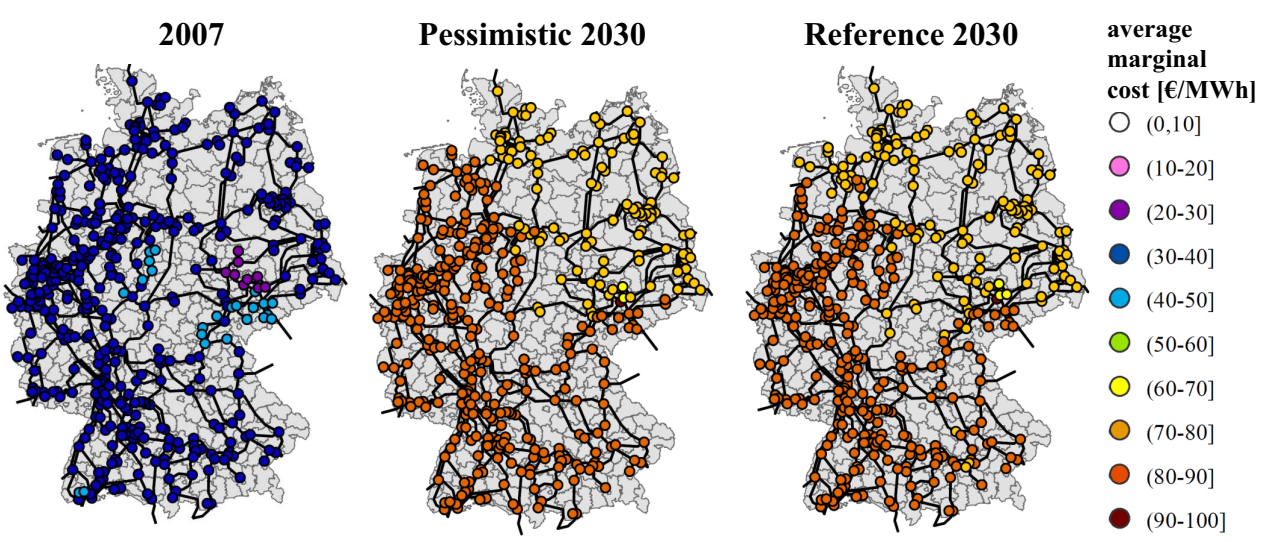

Fig. 5. Comparison of spatial distributed marginal costs of electricity generation in Germany $[15]$.

generation $(\sim 600 \mathrm{TWh}(\mathrm{REF}), \sim 640 \mathrm{TWh}(\mathrm{REF}), \sim 670 \mathrm{TWh}(\mathrm{OPT}))$ and range from $4 \%$ (OPT) to $5 \%$ (REF). Beside this, Germany becomes a net electricity importer in all scenarios until 2030.

Another aspect which is influenced by BEV are the average marginal costs of electricity generation in Germany, which are given by the PERSEUS-NET-EMO model on NUTS-3 level. Again in Figure 5 the scenarios 'Pessimistic' and 'Reference' in 2030 and the status quo in 2007 are compared. The grid congestion between Bavaria and Thuringia as well as between some parts of north and south Germany appears already in 2007. The bottleneck is even more severe in 2030, where it separates different average marginal costs in front of and behind those bottlenecks. The main reason for this is the expansion of RES and the nuclear phase-out. While the highest electricity demand still occurs in Southwest of Germany the electricity generation developed to a more decentralized one with a high share of RES in Northeast of Germany due to the wind potential. Beside this overall trend the 'Pessimistic' and 'Reference' scenario do not differ significantly even though the 'Reference' scenario shows absolute more RES which normally leads to higher overall system costs. However, in this case the load shift potential which is utilized in the 'Reference' scenario lessens this effect or even converts it at least in some nodes mainly in northern Germany. 


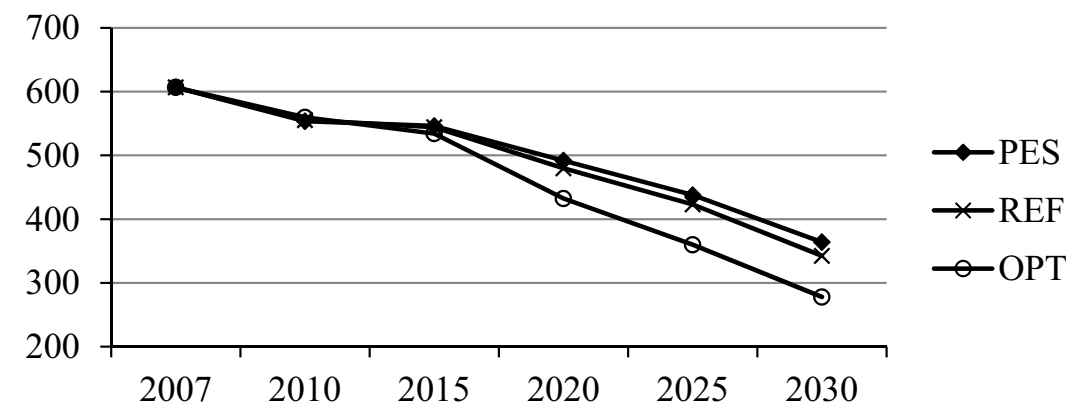

Fig. 6. Comparison of specific $\mathrm{CO}_{2}$ emissions of electricity generation.

The last, but not the least important result we want to highlight are the specific $\mathrm{CO}_{2}$ emissions in Germany and how they vary between the scenarios over time (s. Figure 6). Even though in the 'Reference' and 'Optimistic' scenario more lignite and hardcoal are fired for electricity production their higher RES amount allows to overcompensate for this in terms of specific $\mathrm{CO}_{2}$ emissions. When adding the different scenario assumptions for the specific electricity demand of $\mathrm{BEV}$ in the calculation, the 'Reference' and 'Optimistic' scenarios perform even better in terms of average specific $\mathrm{CO}_{2}$ emissions of $\mathrm{BEV}$ (2030: $78 \mathrm{~g}_{\mathrm{CO}_{2}} / \mathrm{km}(\mathrm{PES}), \sim 67 \mathrm{~g}_{\mathrm{CO}_{2}} / \mathrm{km}(\mathrm{REF})$, $\left.\sim 49 \mathrm{~g}_{\mathrm{CO}_{2}} / \mathrm{km}(\mathrm{OPT})\right)$. Compared to predictions of average $\mathrm{CO}_{2}$ emissions for conventional vehicles of about 80 to $90 \mathrm{~g}_{\mathrm{CO}_{2}} / \mathrm{km}[23] \mathrm{BEV}$ can show a better $\mathrm{CO}_{2}$ emission performance dependent on the framework conditions. Despite this the impact of import and export of electricity on the national $\mathrm{CO}_{2}$ emissions is marginal (about 2-5\%) and decreases over time due to an Europe-wide increase in RES.

\section{Conclusions}

In our analysis BEV influences the electricity system only to a small amount in terms of power plant capacity and electricity generation in Germany. Other trends or political targets like reducing the gross electricity demand or expanding RES show more dominant effects on the German electricity system. However, the high potential of BEV to shift their load shows the ability to help integrating RES as well as reduce the costs of this integration. This holds true even if the technically possible feed-in of BEV back into the grid is neglected.

Beside this BEV show lower specific $\mathrm{CO}_{2}$ emissions compared to conventional cars. They are even lower than the political targets announced for the transport sector. However, for a in-depth conclusion regarding the environmental performance of BEV electricity generation provides only a part of this analysis. For such an analysis all relevant environmental aspects of needed materials and processing (i.e. for the batteries or the mining of coal) as well as their recycling have to be taken into account. Nevertheless, BEV seems to be a promising option helping to reduce the environmental impact of the transport sector. Additionally, BEV can even contribute to cope with the challenges in the energy sector by providing its load shift potential and thereby increasing the electricity feed-in by RES. This, however, depends on the framework conditions (which might be influenced by politics).

Beside these more or less nationwide aspects the market penetration of BEV shows a concentration in urban regions. On this regional scale the impact on distribution grids gains in importance. Distribution grids in urban areas are often designed in a way that allows a high integration of BEV under the premise of a load control [18]. 
But only the interaction of all grid levels allows for a profound analysis of all effects of $\mathrm{BEV}$ on the security of electricity supply. Especially as recent studies came up with a new stability measure for transmission grids [38] as well as with analysis combining this indicator with BEV [39]. Therefore the impact of regional BEV distribution on grids needs further analysis and and a more realistic load flow calculation (i.e. AC instead of DC) would be one next possible step to improve the research in this field.

\section{References}

1. T. Gnann, P. Ploetz, A. Kuehn, M. Wietschel, Transportation Res. Part A: Policy Pract. $\mathbf{7 7}, 95(2015)$

2. B. Nykvist, M. Nilsson, Nat. Climate Change 5, 329 (2015)

3. S. Babrowski, H. Heinrichs, P. Jochem, J. Power Sources 255, 283 (2014)

4. Egbue, O., Long, S., Energy Policy 48, 717 (2012)

5. T.R. Hawkins, O.M. Gausen, A.H. Strømman, J. Life Cycle Assessment 17, 997 (2012)

6. T.R. Hawkins, B. Singh, G. Majeau-Betez, H. Strømman, J. Ind. Ecol. 17, 53 (2012)

7. J. Link, Elektromobilitaet und erneuerbare Energien: Lokal optimierter Einsatz von netzgekoppelten Fahrzeugen (Shaker Verlag, Aachen, 2012)

8. F. Hacker, R. Harthan, F. Matthes, W. Zimmer, Environmental impacts and impact on the electricity market of a large scale introduction of electric cars in Europe - Critical Review of Literature (ETC/ACC Technical Paper 2009/4, 2009)

9. P. Jochem, S. Babrowski, W. Fichtner, Transportation Res. A: Policy Pract. accepted, doi: 10.1016/j.tra.2015.05.007 (2015)

10. J. Kiviluoma, P. Meibom, Energy 35, 1244 (2010)

11. S. Babrowski, Bedarf und Verteilung elektrischer Tagesspeicher im zuknftigen deutschen Energiesystem (KIT Scientific Publishing, Karlsruhe, 2015)

12. R. Follmer (ed.) Mobilitaet in Deutschland 2002, (infas - Institut fr angewandte Sozialwissenschaft / Bundesministerium fr Verkehr, Bau und Stadtentwicklung, Berlin, 2002)

13. A. Kihm, S. Trommer, M. Mehlin, The 91st annual meeting of the transportation research board (TRB) (Washington, 13-17 January, 2013)

14. S. Trommer, A. Kihm, P. Hebes, M. Mehlin, European Transport Conference (ETC), (Glasgow, 2010)

15. H.U. Heinrichs, Analyse der langfristigen Auswirkungen von Elektromobilitaet auf das deutsche Energiesystem im europaeischen Energieverbund (KIT Scientific Publishing, Karlsruhe, 2013)

16. Eurostat, NUTS - Nomenclature of territorial units for statistics, http://ec. europa.eu/eurostat/web/nuts/overview

17. R.C. Green II, L. Wang, M. Alam, Renewable Sustainable Energy Rev. 15, 544 (2011)

18. T. Pollok, C. Matrose, T. Dederichs, A. Schnettler, E. Szczechowicz, Proc. 21st Intern. Conf. Exhib. Electr. Distrib. (CIRED, Frankfurt, Germany, 2011)

19. R.A. Waraich, M.D. Galus, C. Dobler, M. Balmer, G. Andersson, K.W. Axhausen, Transportation Res. Emerging Technol. 28, 74-86 (2013)

20. BMWi and BMU, Energiekonzept fr eine umweltschonende, zuverlaessige und bezahlbare Energieversorgung (2010), http://www.bundesregierung.de/ContentArchiv/DE/ Archiv17/_Anlagen/2012/02/energiekonzept-final .pdf?__blob=publicationFile\& $\mathrm{v}=5$

21. S. Pfahl, P. Jochem, W. Fichtner, Proceedings of EVS27 Conference (Barcelona, Spain, 2013)

22. European Commission, Verordnung (EG) Nr. 443/2009 des Europaeischen Parlaments und des Rates vom 23. April 2009 zur Festsetzung von Emissionsnormen fuer neue Personenkraftwagen im Rahmen des Gesamtkonzepts der Gemeinschaft zur Verringerung der $\mathrm{CO}_{2}$-Emissionen von Personenkraftwagen und leichten Nutzfahrzeugen (2009) 
23. C. Thiel, J. Schmidt, A. Van Zyl, E. Schmid, Transport Res. A.-Policy Pract. 63, 25 (2014)

24. Kraftfahrt-Bundesamt (2015) http://www.kba.de/DE/Statistik/Fahrzeuge/ Neuzulass-ungen/2014_n_jahresbilanz.html?nn=644522

25. J. Rosen, Dissertation, Universitaet Karlsruhe (TH) (Karlsruhe, 2007)

26. C. Böhringer, T.F. Rutherford, J. Econ. Dyn. \& Control 33, 1648 (2009)

27. A. Eßer-Frey, Analyzing the regional long-term development of the German power system using a nodal pricing approach (KIT Scientific Publishing, Karlsruhe, 2012)

28. ENTSO-E, ENTSO-E Interconnected Network Grid Map (2008)

29. EnLAG, BGBl 1, 2870 (2009)

30. German Grid Agency, Netzentwicklungsplan 2014 (2015) http://www . netzentwicklungsplan.de/_NEP_file_transfer/NEP_2014_2_Entwurf_Teil1.pdf

31. German Grid Agency, Feststellung des Reservekraftwerksbedarfs für den Winter 2015/2016 sowie die Jahre 2016/2017 und 2019/2020 (2015) http://www. bundesnetzagentur.de/SharedDocs/Downloads/DE/Sachgebiete/Energie/ Unternehmen_Institutionen/Versorgungssicherheit/Berichte_Fallanalysen/ Feststellung_Reservekraftwerksbedarf_1516_1617_1920.pdf?__blob=publication File\& $v=2$

32. L. Boerjeson, M. Hoejer, K.-H. Dreborg, T. Ekvall, G. Finnveden, Future 38, 723 (2006)

33. T. Gnann, P. Ploetz, Renewable and Sustainable Energy Rev. 47, 783 (2015)

34. T. Ketelaer, T. Kaschub, P. Jochem, W. Fichtner, Int. J. Environ. Sci. Technol. 11, 2169 (2014)

35. BMVBS, Mobilitaet in Deutschland 2008 (2010), http://www.mobilitaet-indeutschland.de/02_MiD2008/index.htm

36. L. Linen, A. Schulz, S. Mischinger, H. Maas, C. Guenther, O. Weinmann, et al., Netzintegration von Fahrzeugen mit elektrifizierten Antriebssystemen in bestehende und zukuenftige Energieversorgungsstrukturen (FZJ Verlag, Advances in Systems Analysis 1 (Bd. 15), Juelich, 2012)

37. J. Swan, in Practical Financial Modelling, 2nd edn. (CIMA Publishing, Oxford, 2008)

38. M. Rohden, A. Sorge, D. Witthaut, M. Timme, Chaos 013123, (2014)

39. A. Gajduk, M. Todorovski, J. Kurths, L. Kocarev, New J. Phys. 16, (2014) 


\section{Repository KITopen}

Dies ist ein Postprint/begutachtetes Manuskript.

Empfohlene Zitierung:

Heinrichs, H. U.; Jochem, P.

Long-term impacts of battery electric vehicles on the German electricity system.

2016. European Physical Journal: Special Topics, 225.

doi: $10.5445 / I R / 1000056399$

Zitierung der Originalveröffentlichung:

Heinrichs, H. U.; Jochem, P.

Long-term impacts of battery electric vehicles on the German electricity system. 2016. European Physical Journal: Special Topics, 225 (3), 583-593.

doi:10.1140/epjst/e2015-50115-x 